\title{
COMPARISON OF POZZOLANIC ADDITIVES FOR NORMAL AND HIGH STRENGTH CONCRETE
}

\author{
Janis Justs, Genadij Shakhmenko, Diana Bajare, Nikolajs Toropovs
}

Riga Technical University, Institute of Materials and Structures

Kalku 1, Riga, LV 1685, Latvia

Ph.: +(371)29724488, fax: +(371)67089248, e-mail: janis.justs@ @rtu.lv

\begin{abstract}
Microsilica is widely recognized as a "benchmark" for pozzolanic products. Although microsilica is an industrial byproduct, it has recently become very expensive. Four different pozzolanic additives were compared by the authors of this study. Two of the additives were commercially available products microsilica by Elkem and Centrilit NC by MC Bauchemie. The other two additives were produced under laboratory conditions. Both of them were clay-based materials. Compressive strength was determined after 7, 28 and 155 days. The objective of this research was to determine alternatives to microsilica and evaluate pozzolanic additives performance in normal and high-strength concrete.
\end{abstract}

Keywords: compressive strength, metakaolin, microsilica, pozzolanic reaction.

\section{Introduction}

Pozzolanic additives are the materials that can improve concrete properties such as concrete strength, durability and impermeability. They are used either as partial substitutes of Portland cement or as an addition [1]. The main component of pozzolanic additives is usually active $\mathrm{SiO}_{2}$ in the amorphous phase. Pozzolanic reaction is a simple acid-based reaction between calcium hydroxide $\left(\mathrm{Ca}(\mathrm{OH})_{2}\right)$ and silicium acid $\left(\mathrm{H}_{4} \mathrm{SiO}_{4}\right)$ [2]. Mechanism of pozzolanic reaction between microsilica and calcium hydroxide in water solution has been investigated particulary by Grutzeck et al [3]. According to this study, during the first hour of getting in contact with water, gel is formed on the surface of microsilica particles that is rich in silicium and poor in calcium. In presence of water microsilica particles form agglomerates. After a while, the gel on the surface of microsilica particles dissolved and microsilica agglomerates started reacting with calcium hydroxide thus forming calcium hydrosilicates. In the presence of cement the above mentioned mechanism becomes more complicated. In this case, microsilica absorbs lime containing water, forms silicium-rich gel and consumes most of the available water. Gel particles clump together and fill the voids between the cement particles and agglomerates in bigger masses. Within the first 15 minutes up to one hour, calcium hydrosilicate particles that do not contain water are enclosed by microsilica gel. In case of ordinary concrete, approximately 3 hours later discrete calcium hydroxide crystals are formed in pores, however when pozzolanic admixtures are used such weak crystals are not formed because excess lime reacts with the surface of silicium-rich gel thus forming calcium hydrosilicates, which is a stronger binder phase than calcium hydroxide. The reactivity of pozzolans is closely linked to the silicate and alumosilicate content in the amorphous phase as well as to the fineness of the material (surface area available for reaction). The influence of superplasticizer on the performance of concrete is reviewed in this paper as well. Previously, the influence of superplasticizer was studied by many authors [4; 5]. At present, superplasticizers play an important role in concrete mix composition (especially in case of high and ultra-high strength concrete), where reduction of water amount is necessary to obtain higher compressive strength. When dry particles are mixed with small amount of water, the electric charges upon the solid particles tend to cause their aggregation and prevent free distribution of the water between solid particles, thus preventing ultimately an optimal repartition of the hydrates formed between the particles. Superplasticizer lowers the surface 
tension of water. Superplasticizer addition to water is mandatory to allow penetration of the fluid in between the solid particles. A high level of fluidity can be maintained in spite of the low water content by the use of only small amounts of superplasticizers. Better pumping behavior for better shuttering or mold injection and a high-strength final concrete can be obtained. The kinetics of chemical mechanisms and the structural organization of particles and their cohesion are deeply influenced by superplasticizers even in small quantity.

\section{Materials and methods}

Local raw materials, commercially available pozzolanic additives, and laboratory produced pozzolanic additives were used in this study. The materials used in this study are: Portland cement CEM I 42,5; coarse aggregate 5/20; coarse aggregate 2/12; sand 0/4; dolomite powder; microsilica 920D (Elkem); Centrillit NC (MC Bauchemie); metakaolin; dehydroxilated illite clay; polycarboxilate-based superplasticizer; water. Chemical composition of pozzolanic materials (similar materials were used in this study) was earlier determined by other authors $[6 ; 7 ; 8]$. The results are given in the Table 1 .

Table 1.

Chemical composition of Portland cement and pozzolans

\begin{tabular}{|c|c|c|c|c|c|c|c|c|}
\hline & \multicolumn{8}{|c|}{ Mass percentage } \\
\hline & $\mathrm{SiO}_{2}$ & $\mathrm{Al}_{2} \mathrm{O}_{3}$ & $\mathrm{Fe}_{2} \mathrm{O}_{3}$ & $\mathrm{CaO}$ & $\mathrm{MgO}$ & $\mathrm{Na}_{2} \mathrm{O}+\mathrm{K}_{2} \mathrm{O}$ & $\mathrm{SO}_{3}$ & LOI \\
\hline Portland cement & 21,0 & 4,63 & 2,26 & 65,6 & 1,18 & 0,94 & & 0,99 \\
\hline Metakaolin & 52,1 & 41,0 & 4,32 & 0,07 & 0,19 & 0,89 & & 0,6 \\
\hline Illite clay & 54,83 & 19,05 & 6,0 & 9,39 & 1,77 & 3,65 & 2,9 & 1,48 \\
\hline Microsilica & 92,0 & 0,7 & 1,2 & 0,2 & 0,2 & 2,0 & & 3,0 \\
\hline
\end{tabular}

Nine concrete mixes were produced by using four different pozzolanic additives. Dolomite powder was applied as filler for the reference mix. Two additives were commercially available: Microsilica 920D from Elkem and Centrillit NC (alumosilicate in slurry form) from MC Bauchemie. The other two were prepared under laboratory conditions from natural clay minerals, the first of those being kaolinite clay (not found on the territory of Latvia) and the second being illite clay (widely found in Latvia). Clay was dried at the temperature of $100^{\circ} \mathrm{C}$ and burned at the temperature of $700^{\circ} \mathrm{C}$, by using the algorithm shown in Fig. 1. Metakaolin was obtained from kaolin - a sedimentary rock that contains hydrated alumosilicate $\mathrm{Al}_{4}(\mathrm{OH})_{8}\left(\mathrm{Si}_{4} \mathrm{O}_{10}\right)$ [9]. In the calcination process at $600^{\circ} \mathrm{C}$ kaolin starts losing crystalline water and transforms into amorphous metakaolin. At the temperature above $900^{\circ} \mathrm{C}$ metakaolin turns into glassy phases, such as cristobalite $\left(\mathrm{SiO}_{2}\right)$ and mullite $\left(\mathrm{Al}_{6} \mathrm{Si}_{2} \mathrm{O}_{23}\right)$, which no longer possesses any pozzolanic reactivity [10]. 


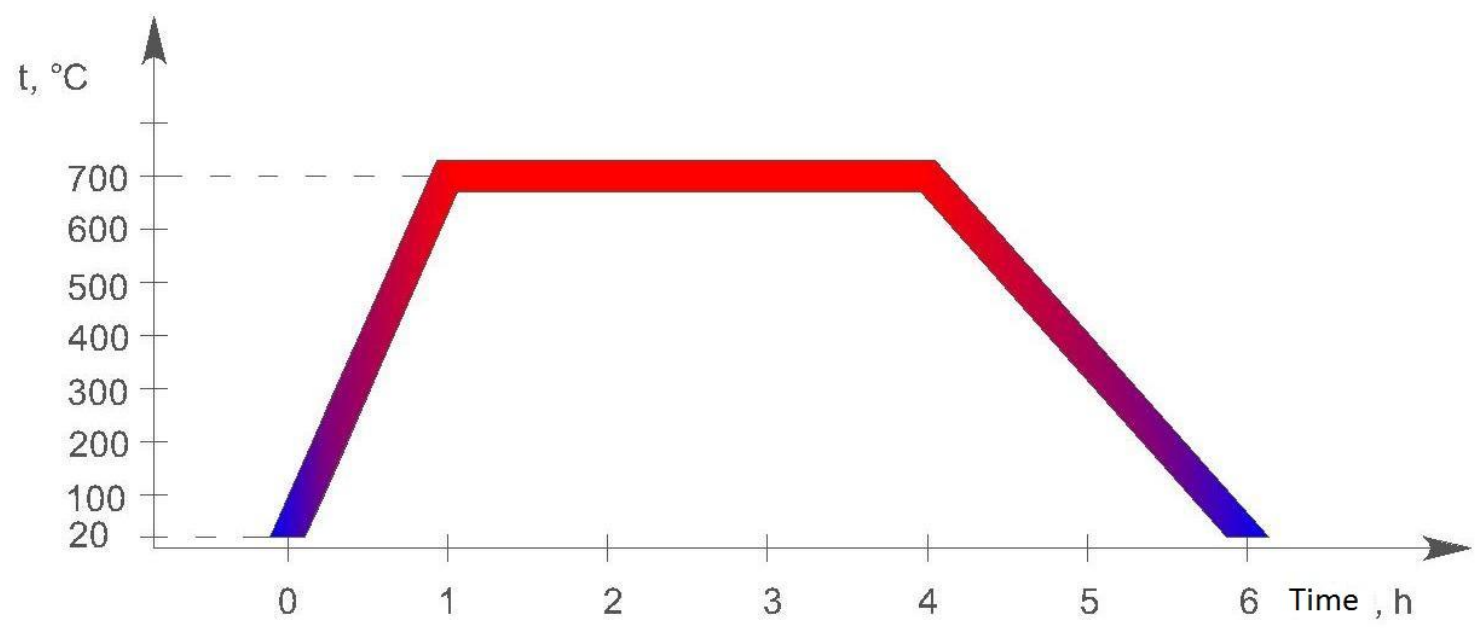

Fig. 1. Temperature regime for clay dehydroxillation

After the process of calcination the materials were ground in the planetary ball mill for 7 minutes. Concrete compositions were mixed in the activating mixer according to the following procedure: all dry materials were mixed till a homogenous mixture was built (approximately for $1.5 \mathrm{~min}$ ). Then water and superplasticizer were added in two steps. During the first step approximately $60 \%$ of water was added. During the second step the rest of the water and the full amount of superplasticizer were added. This procedure was used to achieve a more effective use of the superplasticizer, since superplasticizer can be absorbed by the dry aggregate thus reducing the plasticizing effect. Duration of wet mixing was approximately 5 minutes.

\section{Concrete mix compositions, testing procedure}

Nine different concrete mixes were produced. Five mixes were produced without adding superplasticizer and four mixes contained superplasticizer. The water/cement ratio for the first five mixes was 0.61 and for the rest four mixes -0.48 . Concrete mix composition is given in Table 2.

\section{Concrete mix compositions}

\begin{tabular}{l|ccccccccc} 
Material & DP & MK & IC & MS & CNC & DP/SP & MK/SP & MS/SP & CNC/SP \\
\hline Portland cement 42,5 R & 350 & 350 & 350 & 350 & 350 & 350 & 350 & 350 & 350 \\
Coarse aggregate 5/20 mm & 500 & 500 & 500 & 500 & 500 & 500 & 500 & 500 & 500 \\
Coarse aggregate 2/12 mm & 500 & 500 & 500 & 500 & 500 & 500 & 500 & 500 & 500 \\
Sand 0/4 mm & 750 & 750 & 750 & 750 & 750 & 750 & 750 & 750 & 750 \\
Dolomite powder & 80 & & & & & 80 & & & \\
Metakaolin & & 80 & & & & & 80 & & \\
Dehydrox. illite clay & & & 80 & & & & & & \\
Microsilica & & & & 80 & & & & 80 & \\
Centrillit NC & & & & & 80 & & & & 80 \\
Superplasticizer & & & & & & 7 & 7 & 7 & 7 \\
Water & 212 & 212 & 212 & 212 & 212 & 169 & 169 & 169 & 169 \\
W/C & 0,61 & 0,61 & 0,6 & 0,61 & 0,61 & 0,48 & 0,48 & 0,48 & 0,48
\end{tabular}

DP - dolomite powder; MK - Metakaolin; IC - illite clay; MS - Microsilica; CNC - Centrillit NC; DP/SP dolomite powder, mix with superplasticizer; MK/SP - metakaolin, mix with supeplasticizer; MS/SP Microsilica, mix with superplasticizer; CNC/SP - Centrillit NC, mix with superplasticizer. 
Cone slump test results varied a little depending on different pozzolanic additives yet all the time stayed within the limits of the class S3. By applying superplasticizer it is possible to reduce the w/c ratio while maintaining the same cone slump result as without the superplasticizer. The effect of superplasticizer is also manifested through better dispersion of fine particles in the mix. Compressive strength was determined at the age of 7, 28 and 155 days. The pressure was applied at the rate of $0.75 \mathrm{MPa} / \mathrm{s}$. Concrete samples were hardening under water at the temperature of $20^{\circ} \mathrm{C}$ for 28 days; during the remaining time hardening happened in the air at $20^{\circ} \mathrm{C}$. Mixes without superplasticizer and with the w/c ratio of 0.61 were considered as normal-strength concrete mixes and mixes where superplasticizer was used and the w/c ratio was 0.48 were considered as high-strength concrete mixes.

\section{Testing results and discussion}

Four different pozzolanic admixtures: microsilica, metakaolin, Centrillit NC and dehydroxilated illite clay were compared with the reference mix containing dolomite powder. The same concrete mixes were produced with and without superplasticizer. The results of compressive strength at 7,28 and 155 days for the samples that did not contain superplasticizer can be seen in Fig. 2 and Fig. 3. The results demonstrated that in the first five experimental series (without superplasticizer) the compressive strength at the age of 7 days varied from $26.6 \mathrm{MPa}$ for the reference mix to $40.4 \mathrm{MPa}$ for the samples containing metakaolin.

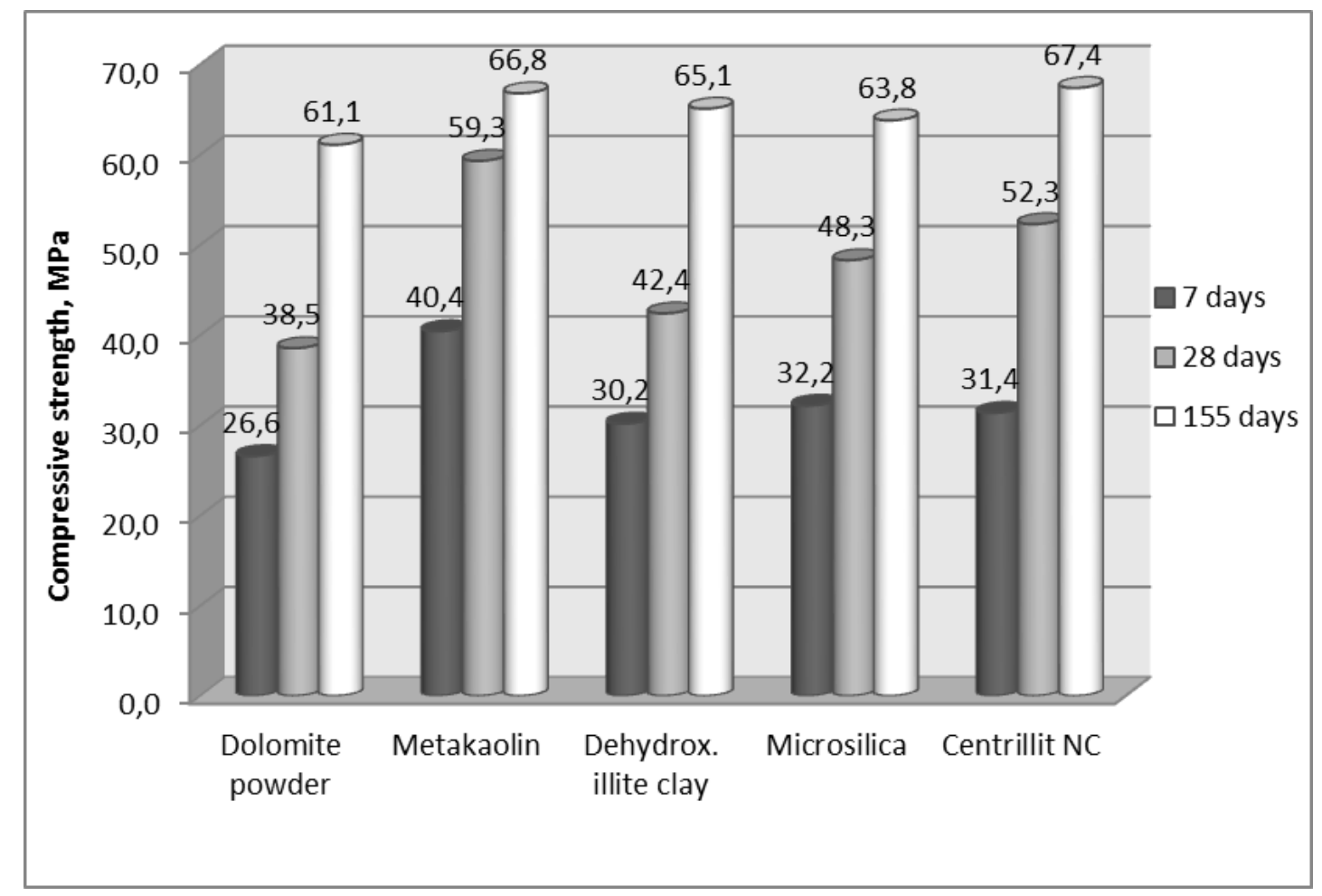

Fig 2. Compressive strength of normal strength samples without superplasticizer

Results for dehydroxilated illite clay, microsilica and Centrillit NC at the age of 7 days were very similar: $30.2 \mathrm{MPa}, 32.2 \mathrm{MPa}$ and $31.4 \mathrm{MPa}$ accordingly. Rapid strength gain for metakaolin can be explained by high content of $\mathrm{Al}_{2} \mathrm{O}_{3}$ and high reactivity with calcium hydroxide. At the age of 28 days the highest compressive strength of $59.3 \mathrm{MPa}$ was obtained for metakaolin thus proving its high pozzolanic reactivity. The difference in compressive strength compared to the reference mix was as high as 54\%. The lowest strength increase (4.9\% compared to the reference mix) was for the dehydroxilated illite clay. Testing of 
samples at the age of 155 days showed that compressive strength increased from $12.6 \%$ for metakaolin mix to $58.7 \%$ for the reference mix showing that metakaolin tends to use most of its potential in the shorter term. The final 155 day strength varied from $61.1 \mathrm{MPa}$ for the reference mix to 67.4 for Centrillit NC. Microsilica with the indicator $63.8 \mathrm{MPa}$ demonstrated the second result after the reference mix, which proved that it is not possible to fully use its potential without good particle dispersion in the mix and that a high range superplasticizer should be used to obtain good microsilica particle dispersion.

The next experimental series where superplasticizer was applied and the w/c ratio was decreased to 0.48 showed the results that can be seen in Figure 3. At the age of 7 days the compressive strength varied from $40.1 \mathrm{MPa}$ for the reference mix to 52.3 for the samples containing metacaolin, once again proving metacaolin's high early strength development. In comparison to samples without superplasticizer and with higher w/c ratio from the previous five series, strength increase at the age of 7 days is from $8.0 \%$ for the samples with metacaolin to $55.9 \%$ for the samples with microsilica. At the $28^{\text {th }}$ day the highest compressive strength was for microsilica and metakaolin $-73.0 \mathrm{MPa}$ and $68.4 \mathrm{MPa}$ respectively. Finally, at the age of 155 days the dolomite powder samples reached compressive strength of $75.3 \mathrm{MPa}$, while indicators for metakaolin were 89.6 MPa, for microsilica - 99.1 MPa and for Centrillit NC 79.2MPa. The reasons for lower compressive strength for Centrillit NC could be the fact that it was in the slurry form - at a 50/50 proportion with water and because of the possible segregation the distribution of the material in the volume might have been uneven.

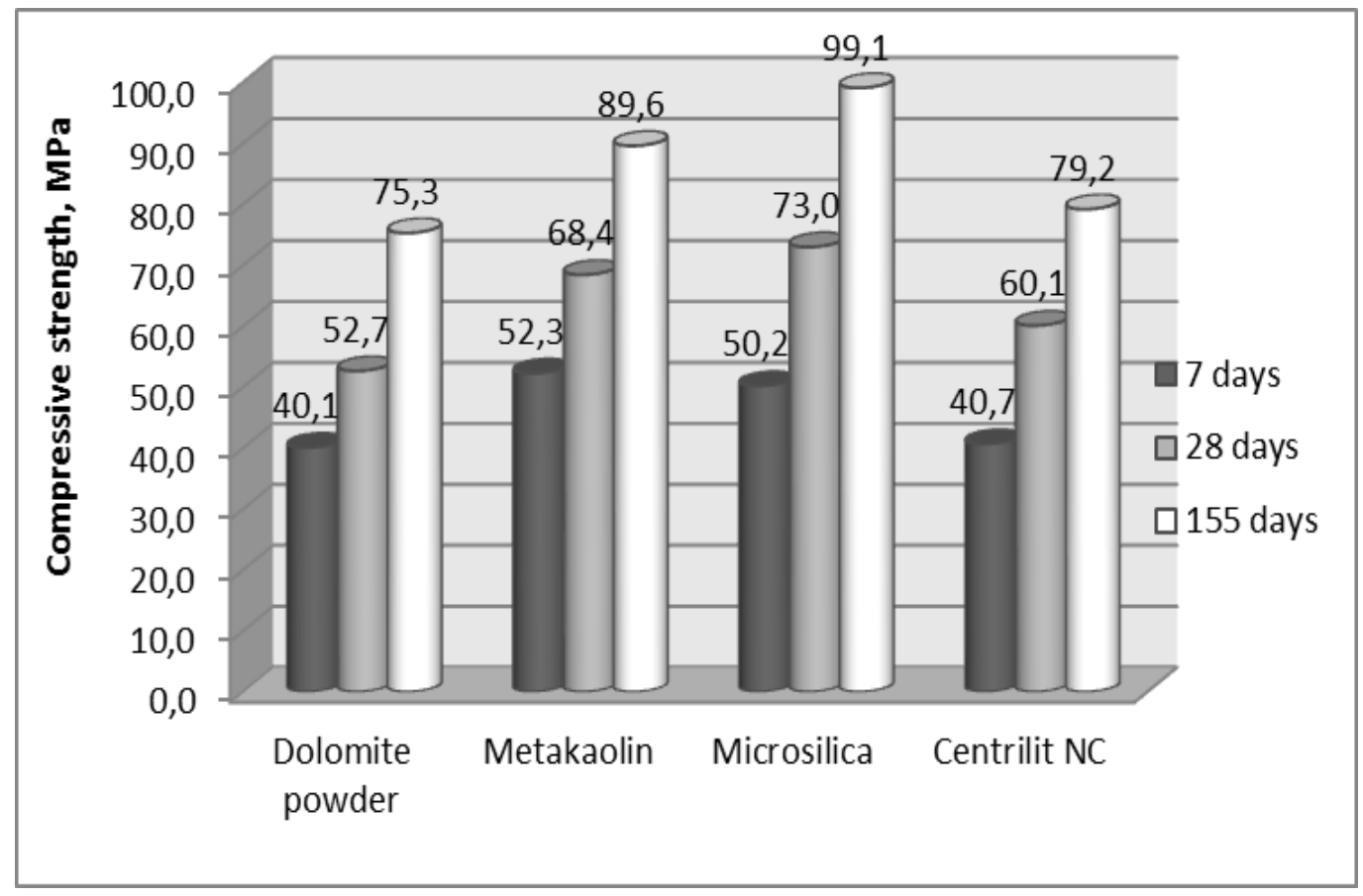

Fig 3. Compressive strength of high strength samples with superplasticizer

\section{Conclusions}

- Specimens were tested at three different ages of 7;28 and 155 days. Normal strength concrete samples (series without superplasticizer) at the age of 28 days showed strength increase from $10.1 \%$ to $54 \%$ compared to the reference mix, showing the positive effect on compressive strength increase by all used additives. The highest gain of compressive strength was demonstrated by the specimens with metakaolin.

- This study demonstrated that without superplasticizer alumosilicate-based additives (metakaolin, and Centrillit NC) perform better than microsilica. 
- Dehydroxilated illite clay recorded a $10.1 \%$ gain in compressive strength compared to the reference mix showing that after the dehydroxilation at $700^{\circ} \mathrm{C}$ this type of material can also exhibit pozzolanic properties.

- In the series of experiments for high strength concrete microsilica demonstrated the highest compressive strength at the age of 28 days, which can be explained by better fine microsilica particle dispersion in the concrete mix.

\section{References}

1. F.M. Lea, The Chemistry of Cement and Concrete, $3^{\text {rd }}$ ed., Edward Arnold, London, 1974.

2. Cook D.J. (1986) Natural pozzolans. In: Swamy R.N., Editor (1986) Cement Replacement Materials, Surrey University Press, p. 200.

3. Grutzeck et al. „Mechanisms of Hydration of Portland Cement Composites Containing Ferrosilicon Dust”, Proceedings , 4th International Conference on Cement Microscopy, Las Vegas, U.S.A., 1982- p. 193-202

4. V.Morin, F.Cohen Tenoudji, A.Feylessoufi and P.Richard, Superplasticizer effects on setting and structuration mechanisms of ultrahigh-performance concrete, Cement and Concrete Research 31 (2001) 6371.

5. J.M.Khatib and P.S.Mangat, Influence of superplasticizer and curing on porosity and pore structure of cement paste, Cement \& Concrete Composites 21 (1999) 431-437.

6. Joshi RC, Lohta RP. Fly ash in concrete. Advances in concrete technology. vol. 2, Amsterdam: Gordon and Breach; 1997.

7. Bai J., Wild S., Sabir BB., Kinuthia JM. Workability of concrete incorporating PFA and metakaolin. Mag Concrete Res., 1999;51(5):207-16.

8. Copernicus Research Project. Recycling of waste clay brick and tile material for the partial replacement of cement in concrete. Research contract No. CIPA-CT94-0211, First annual report, 1996, Second annual report, 1997 and Third annual report, 1998.

9. H.H.Murray and J.E.Kogel, Appl. Clay Sci. 29 (3-4) (2005), p. 199.

10. M.J.Ribeiro, D.U.Tulyagavov, J.M.Ferreira and J.A.Labrincha, J. Eur. Ceram. Soc. 25 (5) (2005), p. 703. 